\title{
Optimizing the Stacking Sequence in Dual-Purpose Body Armours
}

\author{
Ian Horsfall, Celia H Watson, Steve M Champion \\ Department of Engineering and Applied Science, Cranfield University, Shrivenham, \\ Wiltshire. SN6 8LA, United Kingdom \\ Tel: +44 1793 785389, email: i.horsfall@ cranfield.ac.uk
}

\section{Abstract - Paper for the 27th ISB}

Background. Many police body armour systems are dual purpose, offering both ballistic and knife resistance by combining a flexible ballistic textile pack with a stiffer knife resistant layer. The two types of protection differ in materials and mechanisms such that each individual component may help or interfere with the function of the other. This paper investigates the effect on knife and ballistic penetration resistance when a single thin metal plate was placed at various different positions within an aramid textile armour pack. Two metallic layers were used, aluminium 7075 and commercial purity titanium, these had similar areal densities and were positioned in the front, middle and back of a 20 layer pack of woven Kevlar® 49.

Method of Approach. An instrumented drop weight machine was used to deliver a repeatable knife blade impact at comparable energy levels to those specified in UK Home Office test standards for knife resistance. Ballistic tests were used to determine the $V_{50}$ ballistic limit velocity against typical $9 \mathrm{~mm}$ and .357" Magnum handgun threats.

Results. Against a stabbing threat, it was found that positioning the metal plate in the middle of the pack provided the greatest resistance to knife penetration by a factor of almost two. Whilst a plate at the front of the pack provided less resistance and plates positioned at the rear of the pack provided the least resistance to penetration. Against the ballistic threat, the penetration resistance of the textile pack can be significantly improved when a metal plate is at the front of the pack whilst for all other positions the effect is negligible. However, this effect is sensitive to both the ammunition type and the metal plate composition. When the metal plate is positioned at the rear of the pack there is a significant decrease in the back-face deformation of the armour pack although again this effect is only present for certain ammunition and metal combinations.

Conclusions. The overall effect of combining soft and hard elements was that specific performance parameters could be substantially increased by the correct combination. There were no significant negative effects, but in a number of cases the combined systems performance was no greater than that of a single element type, despite the added weight.

Keywords. Body armour, ballistic protection, stab resistance, textile armour. 


\section{Introduction}

To maximise ballistic resistance, textile armour packs need to be strong enough to resist perforation and flexible enough deform and exchange kinetic energy with the bullet [1-3]. Body armours made of layers of woven aramid textiles have been developed so that as the projectile impacts and begins to perforate the layers of aramid, each of the layers are strong enough to deform the projectile before perforation [4]. This mechanism has the effect of increasing the presented area of the projectile, which makes the perforation of each successive layer more difficult as the contact stress is reduced [5]. The armour panel is also forced backwards and driving this motion absorbs some of the impact energy until all of the impact energy has been dissipated [6].

A bullet such as the .357 " Magnum has an initial cross-section of $65 \mathrm{~mm}^{2}$ and after impact can mushroom to a cross-section of up to $254 \mathrm{~mm}^{2}$. The result is that optimized textile ballistic armour tends to consist of a flexible system, which operates by deforming rearwards when struck. In contrast the tip of a knife will have a very small cross-sectional area ranging from as little as $0.2 \mathrm{~mm}^{2}$ for a sharp tip to $2.5 \mathrm{~mm}^{2}$ for a blunt knife [7]. Maximising knife resistance in body armour requires a strong stiff panel, as the energy concentration over such small cross-sectional areas, mean that the energy per unit area at the tip of a knife will be high. Therefore knife armour needs to be relatively hard and typically inflexible in order to prevent immediate penetration. Flexibility can be introduced into knife resistant armour by incorporating a layer of chain mail. Although chain mail is effective, it consists of metal rings which may result in differing performance depending on whether the blade tip strikes in the centre or at the side of a ring. This will inevitably introduce some variability to the perforation results. Multiple layers of woven aramid with coatings are also used to make stiff knife resistant layers in body armour [8-10].

In the present work, monolithic metallic plates were chosen as the knife resistant element in order to provide a repeatable and relatively simple solution, which is still representative of some current designs. In addition, the metal plates mimic the effect of rigid equipment or accessories that might be attached to the armour and are in contact with the ballistic armour pack.

\section{Materials}

The knife resistant layers were; 400mm square, aluminium alloy 7075-T6 (1.5mm thick) and titanium CP Grade $3\left(1.0 \mathrm{~mm}\right.$ thick) these have comparable areal densities of $4.48 \mathrm{~kg} / \mathrm{m}^{2}$ and $4.51 \mathrm{~kg} / \mathrm{m}^{2}$ respectively. Their mechanical properties were measured and are shown in table 1 . Aramid ballistic packs with an areal density of $3.53 \mathrm{~kg} / \mathrm{m}^{2}$ were constructed from twenty $400 \mathrm{~mm}$ squares of high tenacity, high cut resistance Du Pont Kevlar® 49, woven at 7x7 yarns per centimetre and box quilted on a $30 \mathrm{~mm}$ pitch [11]. This enabled a completed metal/Kevlar ${ }^{\circledR}$ composite pack with either of the metallic layers to have an areal density of approximately $8 \mathrm{~kg} / \mathrm{m}^{2}$ and total thickness of approximately $7 \mathrm{~mm}$. 
Table 1. Material property data for Aluminium and Titanium

\begin{tabular}{lccccc}
\hline Metal Type & $\begin{array}{c}\text { Density } \\
\left(\mathrm{kgm}^{-3}\right)\end{array}$ & $\begin{array}{c}\text { Yield } \\
\text { strength } \\
(\mathrm{MPa})\end{array}$ & $\begin{array}{c}\text { Tensile } \\
\text { strength } \\
(\mathrm{MPa})\end{array}$ & $\begin{array}{c}\text { Elongation } \\
\text { to fail }(\%)\end{array}$ & $\begin{array}{c}\text { Hardness } \\
(\mathrm{Hv})\end{array}$ \\
\hline $\begin{array}{l}\text { Aluminium } \\
\text { Alloy 7075 T6 }\end{array}$ & 2800 & 511 & 581 & 11 & 145 \\
$\begin{array}{l}\text { Titanium CP } \\
\text { Grade 3 }\end{array}$ & 4510 & 275 & 450 & 32 & 201 \\
Kevlar@ 49 & 1.45 & & 3000 & 2.4 &
\end{tabular}

\section{Ballistic tests}

$\mathrm{V}_{50}$ ballistic limit tests were used to evaluate the armour systems. A $\mathrm{V}_{50}$ is the velocity at which $50 \%$ of the shots fired are stopped by the armour and $50 \%$ perforate the armour. Normally this value is obtained from firing six shots within a specified range of velocities. The range (spread) of velocities allowed for a six shot $\mathrm{V}_{50}$ typically needs to be less that $40 \mathrm{~ms}^{-1}$ between the lowest recorded velocity for a perforation and the highest velocity recorded for a stop. [12]

The ammunitions, range setup, procedure and the conditioning of the witness block outlined in the Home Office Scientific and Development Branch's 2007 ballistic standard [13] were followed. Details of the ammunitions are given in table 2. The $9 \mathrm{~mm}$ ammunition has a full metal jacket, which encloses the nose of the projectile whilst the .357" Magnum ammunition has a jacket only around its base with an exposed lead core at the nose. Consequently, the .357" Magnum bullet tends to mushroom rapidly even against soft targets whilst the $9 \mathrm{~mm}$ bullet tends to deform much less easily. All targets were mounted onto a conditioned block of Roma Plastilina ${ }^{\circledR}$ No1. When correctly calibrated this material is recognised as an international standard method of recording the backface deformation caused by ballistic impacts on body armour systems [13-15]. The mean backface deformation caused by the three non-penetrating shots (from 6 shot $\mathrm{V}_{50}$ set), was recorded.

Table 2. Ammunition used in ballistic tests

\begin{tabular}{lll}
\hline Ammunition Description & Manufacturer & Mass(grams) \\
\hline 9x19mm Parabellum & Dynamit Nobel & $8.0 \mathrm{~g}$ \\
Full Metal Jacket & DM11A1B2 & (124 grain) \\
& & \\
.357" Magnum & Norma 19107 & $10.2 \mathrm{~g}$ \\
Semi-Jacketed & & $(158$ grain $)$ \\
Soft Point Flat Nose & & \\
\hline
\end{tabular}




\section{Knife tests}

For the knife tests a Rosand accelerated weight instrumented impact tester type IFW8 was used to deliver repeatable and accurate impacts of known energy. The forces resisting the blade during the test were measured using a calibrated load cell [16], and the total drop mass was $2.3 \mathrm{~kg}$. The test used the No 5 blade from UK Home Office 1993 standard [17] which is a robust 'Bowie' type blade, Fig. 1.

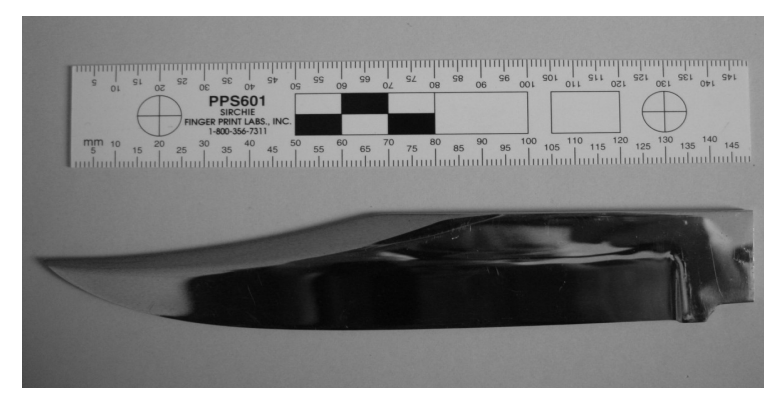

Figure 1. Knife test blade, the UK Home Office number 5 design [17]

Test samples were clamped underneath the drop tower and supported by a Roma Plastilina ${ }^{\circledR}$ No.1 filled tube. The penetration resistance of the 20 layer aramid pack and both metal panels were tested for knife resistance separately, following this further test were conducted with the metal panels were placed either at the front, back or in the middle of the aramid packs. After each test the knife was withdrawn and the Plastilina ${ }^{\circledR}$ block, Fig. 2, was sectioned along the axis of the penetration, exposing the penetration witness mark which allowed the depth of penetration to be measured, [18-20].
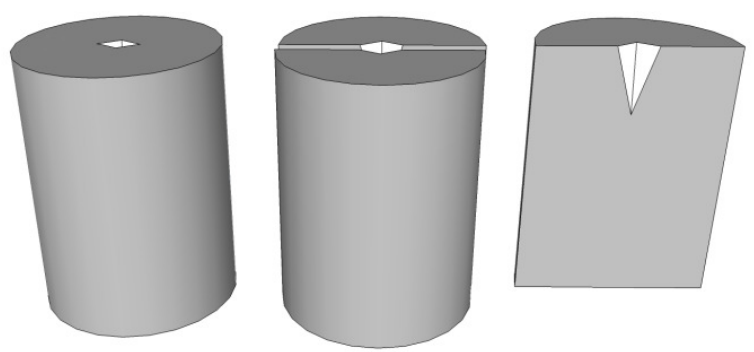

Figure 2. Sectioning the Plastlina ${ }^{\circledR}$ test block to measure depth of penetration

\section{Results - Knife resistance}

The individual components of the test pack were tested in the drop tower for their knife resistance using a range of energies from 4 to 54joules, and compared by plotting the knife penetration (mm) against impact kinetic energy (joules) as shown in Fig. 3. 


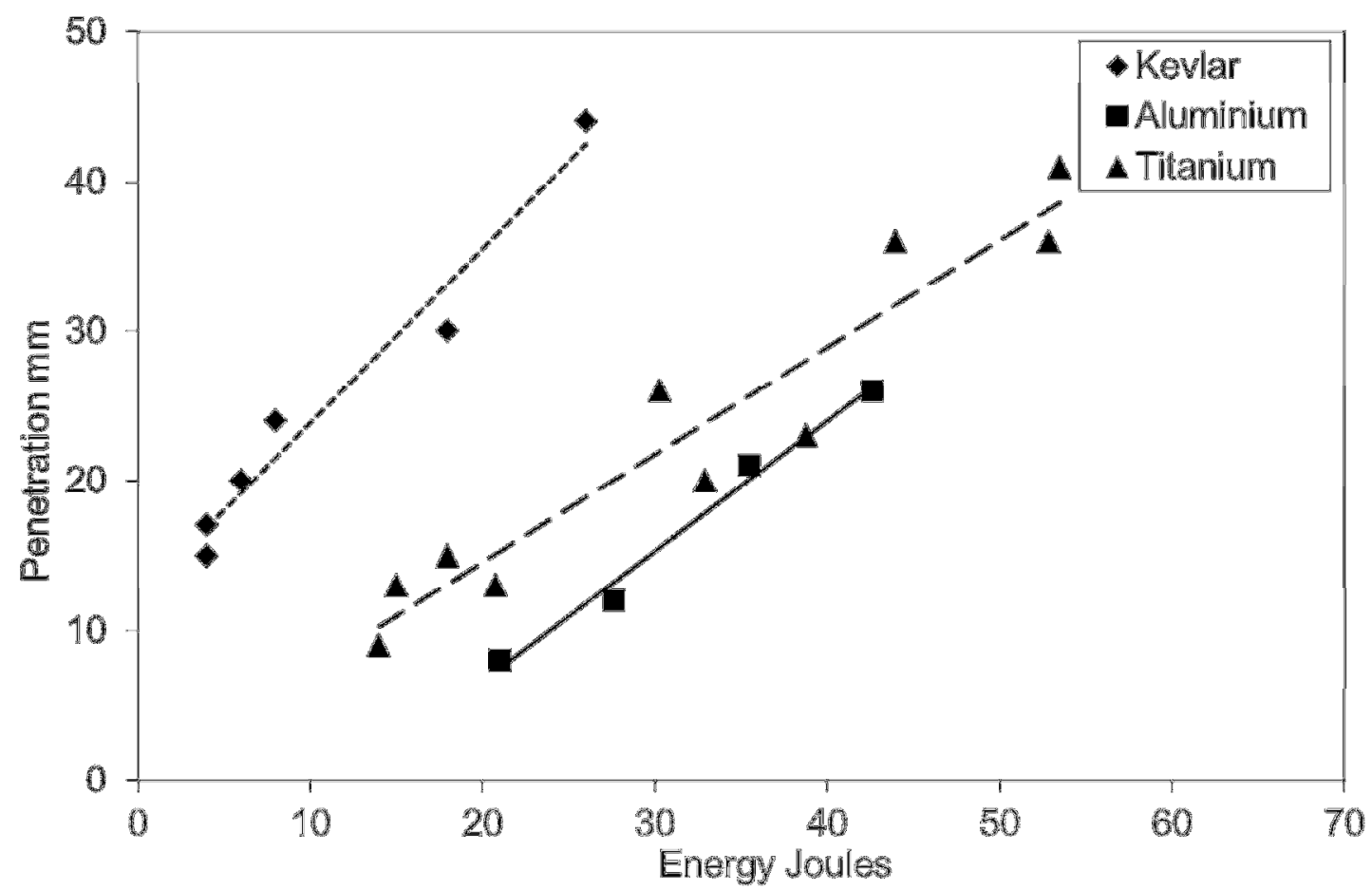

Figure 3. Comparison of the penetration resistance of the individual armour components

As expected the 20 layer aramid pack had the least resistance to penetration with the aramid strands being cut cleanly and a maximum penetration of $44 \mathrm{~mm}$ being reached at 26joules. Aluminium showed the greatest resistance to penetration with $26 \mathrm{~mm}$ of penetration for a 43 joule impact, in comparison to $36 \mathrm{~mm}$ for a 44 joule impact on titanium. The force displacement curves from typical tests are shown in Fig. 4. The aluminium produces a steep rise in force to a peak at only $3 \mathrm{~mm}$ of displacement after which perforation occurs. In contrast, the titanium and aramid packs show a more gradual increase in force up to perforation at approximately $10 \mathrm{~mm}$ displacement and less subsequent drop in force. This is a result of the relatively high stiffness of the aluminium plate leading to a sudden failure whilst the other systems deformed into the Plastilina ${ }^{\circledR}$ block and fail in a less sudden manner. 
Optimizing the Stacking Sequence in Dual-Purpose Body Armours

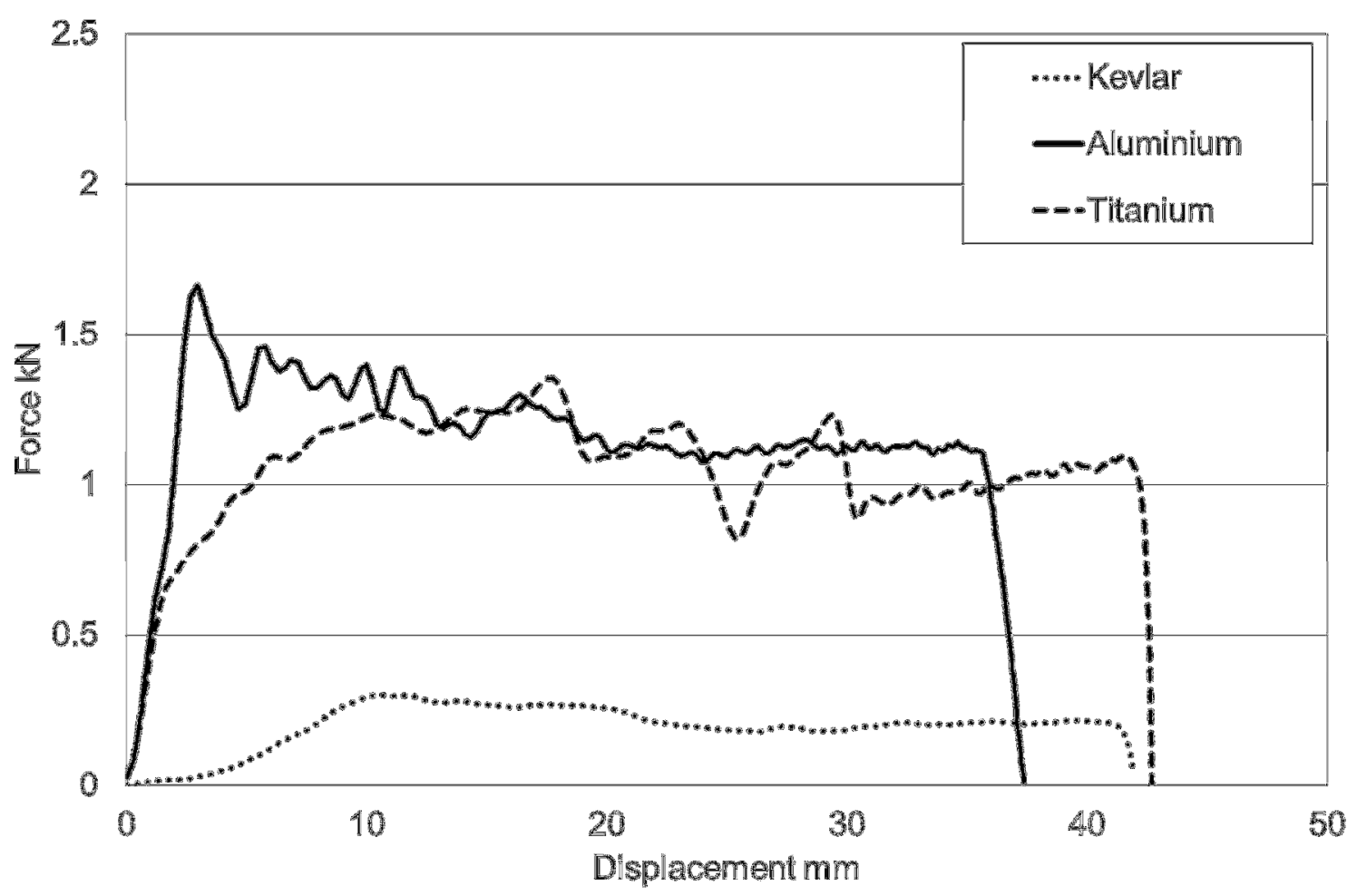

Figure 4. Force vs. displacement graphs of individual components, 20 layer Kevlar® aramid pack, aluminium and titanium sheets.

Aluminium and titanium sheets were then positioned in front of, behind and in the middle of the aramid packs. These composite packs were tested at energies from 40 to 60 joules, with 5 drops carried out at each energy level, Fig. 5. For both metals the system gave the greatest knife resistance when placed in the middle of the pack. For 60joule impacts positioning plates in the middle produced half the depth of penetration of front positioned plates and one third the depth of penetration of back positioned plates. 


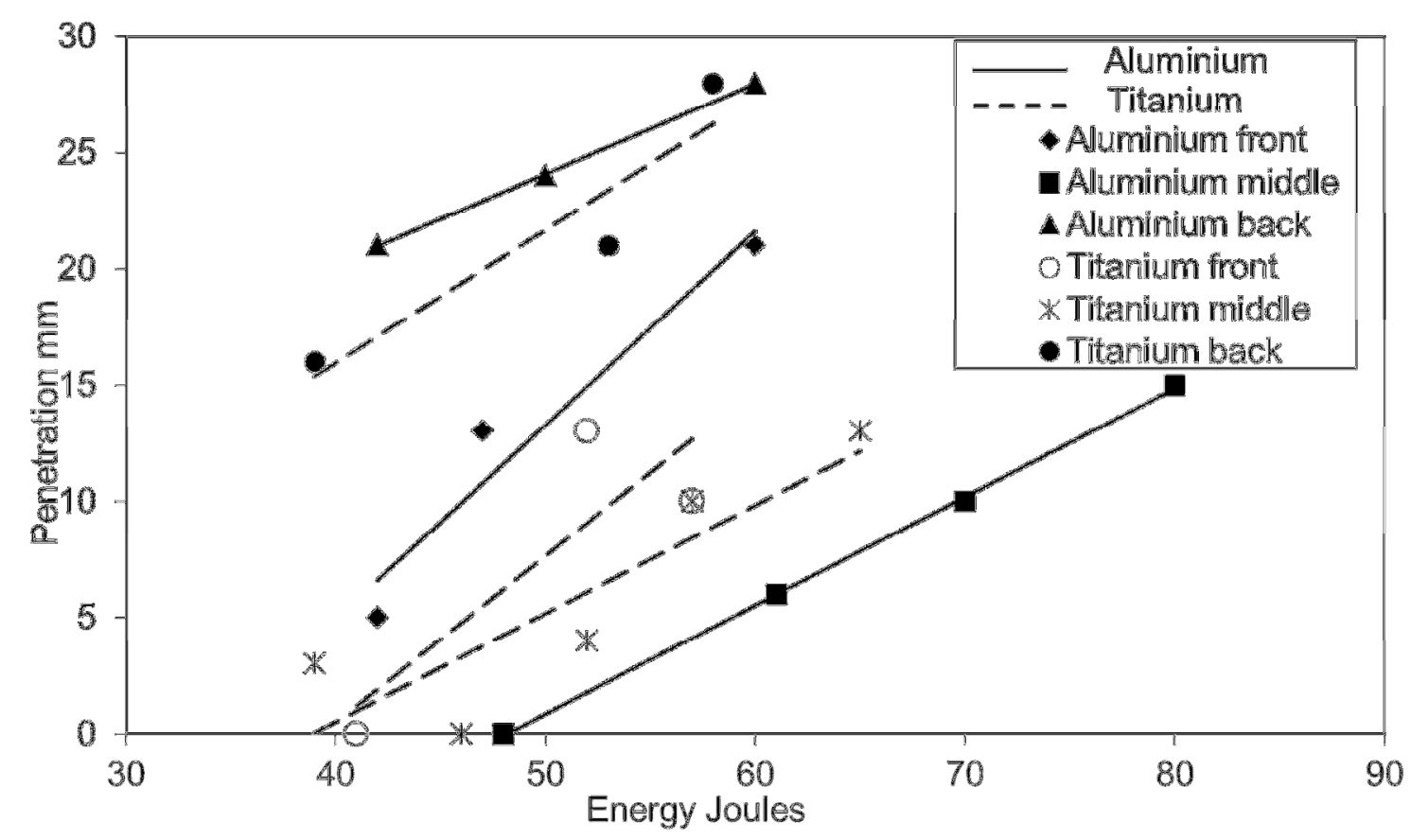

Figure 5. Effect of position of metal plates on knife resistance

Figure 6 shows the force vs. displacement graphs for aluminium plates at the three positions. The curves are seen to be more complex than for the plates in isolation, Fig. 4. For the test shown in figure 6 perforation of the aluminium plate is characterized by a sudden drop in force and subsequent rise, this is seen at $8 \mathrm{~mm}$ displacement for the plate in the front position and between $16 \mathrm{~mm}$ and $18 \mathrm{~mm}$ displacement for the other two positions. It should also be noted that the load at peak is significantly higher when the plate is in the front position.

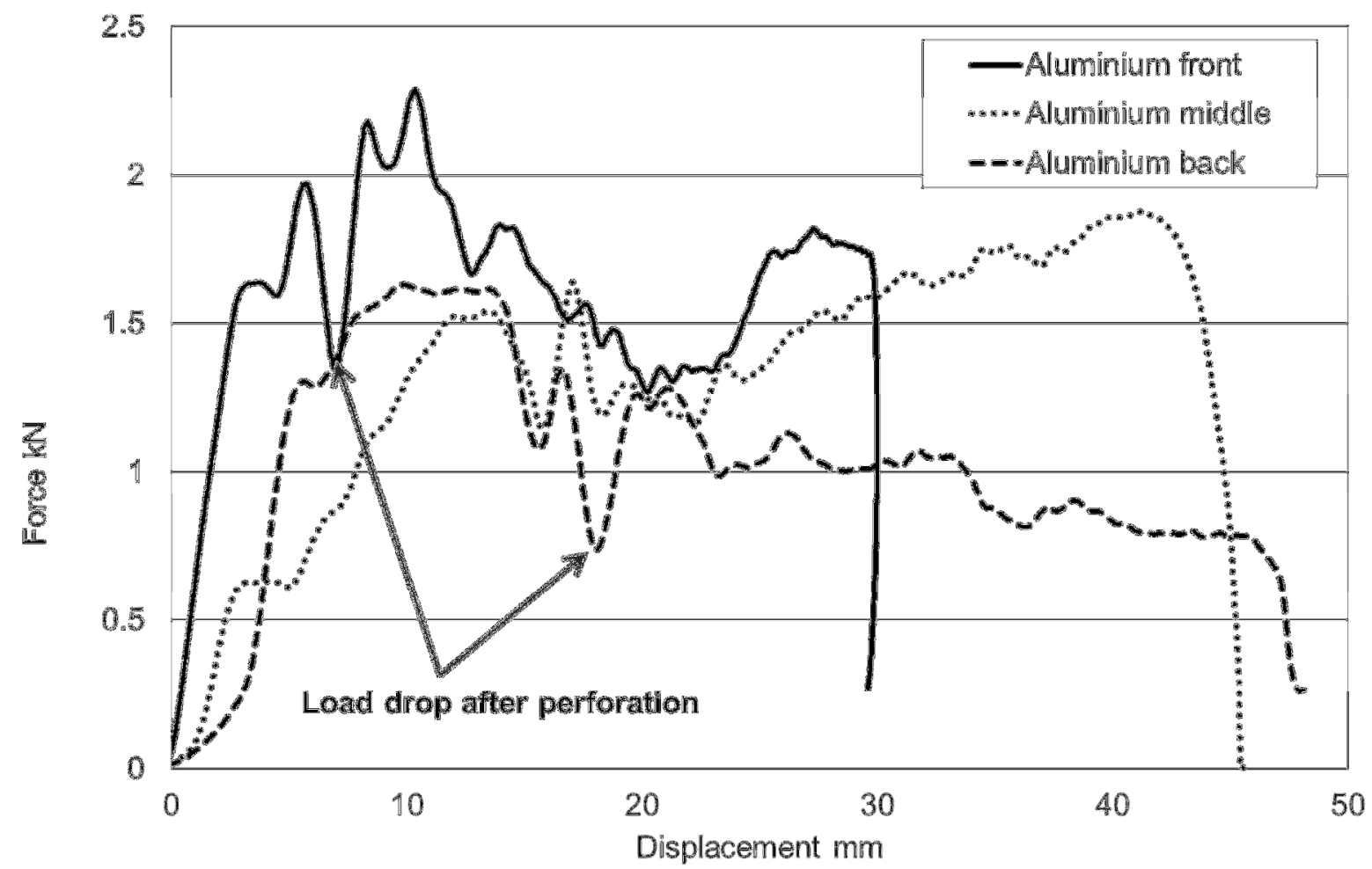

Figure 6. Effect of aluminium plate position on knife penetration force 

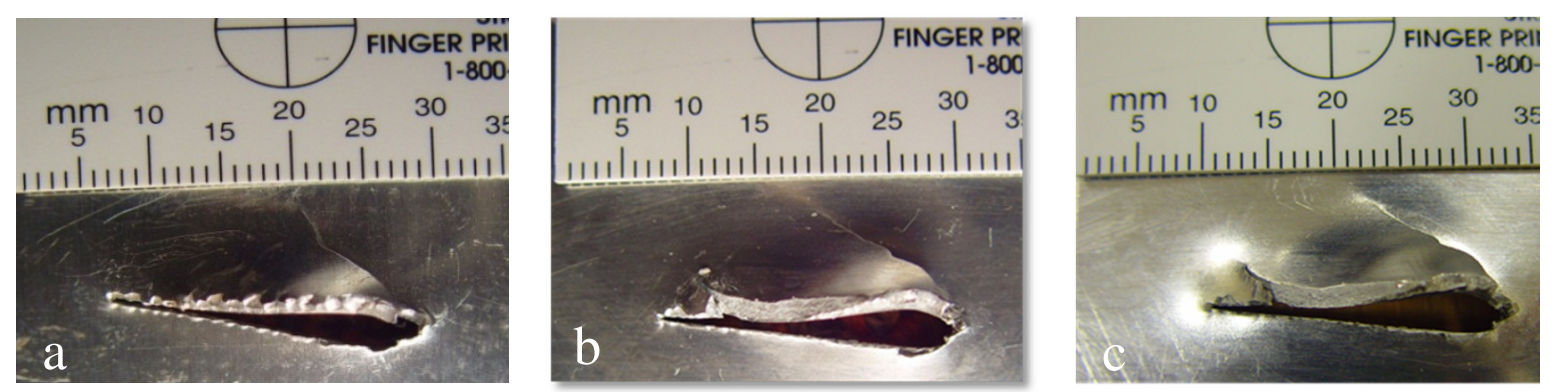

Figure 7. Perforation of aluminium plate showing failure, a) Aluminium at front of aramid showing cut edge and brittle crack, b) Aluminium in middle of aramid, c) Aluminium at back of aramid

Examination of the perforated plates illustrated in Fig. 7 shows a distinct difference in failure mechanism between the in front position and the other two. When positioned at the front the failure is seen to be brittle with a row of chips being present along the rear face of the fracture (figure 7a). For the other two positions, there is a clear shear surface visible at approximately $45^{0}$ to the plane of the plate. The failure mode in this case appears to be the result of membrane stresses causing a relatively ductile, tensile induced shear failure in the plate.. In all three cases there is relatively little deformation other than local deformation of the material in contact with the blade.

For titanium there is less apparent difference in the failure mode with all three plates showing local dishing around the impact site and a relatively ductile failure of the plate. Figure 8 shows the force displacement curves for the titanium samples and Fig. 9 shows the perforated plates.

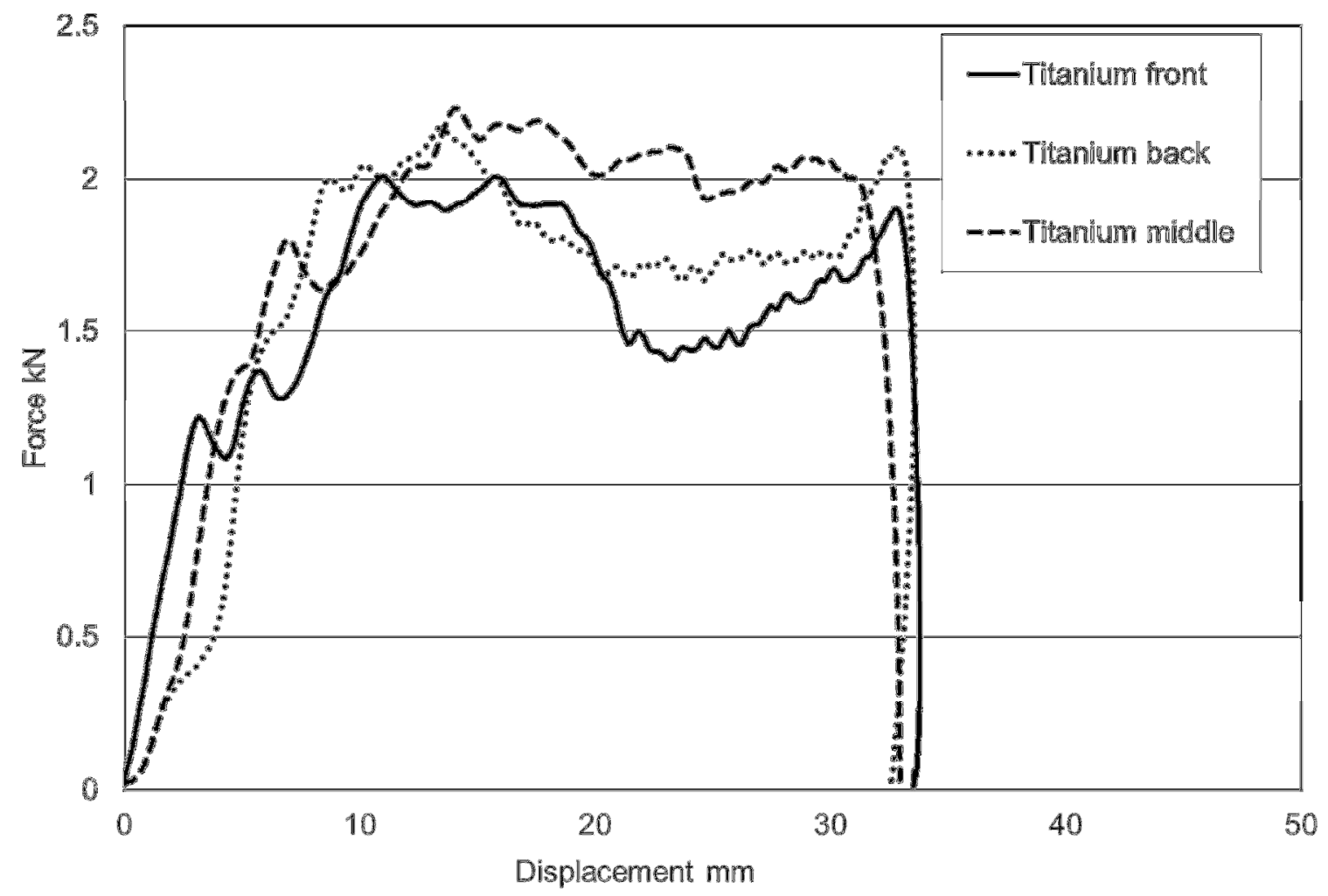

Figure 8. Effect of Titanium plate position on knife penetration force 

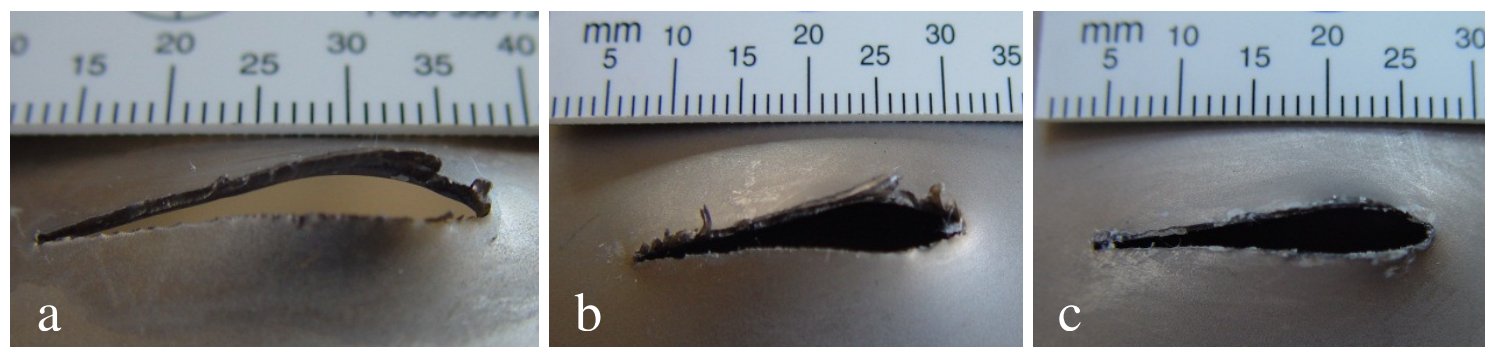

Figure 9. Perforation of titanium plate showing failure, a) Titanium at front of aramid showing cut edge, b) Titanium in middle of aramid, c) Titanium at back of aramid

\section{Results - Ballistic resistance}

To determine the ballistic limit, tests were carried out against 9mm and .357" Magnum ammunitions on the 20 layer aramid packs only. Then the same tests were performed with the metal plates placed in front, middle or at the back of the 20 layer aramid packs. For each construction the $\mathrm{V}_{50}$ ballistic limit velocity was determined using the procedure of STANAG 2920 [12],using 6 shots; 3 perforating and 3 non-perforating. The sample standard deviation (SD) of the individual shot velocities was calculated in order to provide a measure of the spread of data. The backface deformations were measured from the 3 non-penetrating shots and the SD of these was also calculated (except for $9 \mathrm{~mm}$ vs. titanium front where insufficient data was available to provide an estimate of SD).

Table 3. $\mathrm{V}_{50}$ Ballistic limit tests on aramid packs and aluminium and titanium plates with aramid packs

\begin{tabular}{lllllll}
\hline Ammunition & Armour & $\begin{array}{l}\mathbf{V}_{\mathbf{5 0}} \\
\left(\mathbf{m s}^{-\mathbf{1}}\right)\end{array}$ & $\begin{array}{l}\text { Velocity } \\
\text { spread } \\
\left(\mathbf{m s}^{-\mathbf{1}}\right)\end{array}$ & $\begin{array}{l}\text { SD } \\
\left(\mathbf{m s}^{-\mathbf{1}}\right)\end{array}$ & $\begin{array}{l}\text { Backface } \\
\mathbf{d e f o r m a t i o n} \\
(\mathbf{m m})\end{array}$ & $\begin{array}{l}\text { SD } \\
(\mathbf{m m})\end{array}$ \\
\hline 9x19mm Para & Aramid only & 339 & 25 & 8.4 & 49 & 2.1 \\
.357" Magnum & Aramid only & 445 & 33 & 11.9 & 56 & 4.0 \\
\hline 9x19mm Para & Aluminium front & 432 & 27 & 9.8 & 43 & 9.3 \\
& Aluminium middle & 357 & 11 & 4.6 & 56 & 3.2 \\
& Aluminium back & 339 & 24 & 11.9 & 32 & 3.5 \\
.357" Magnum & Aluminium front & 468 & 13 & 5.4 & 54 & 10.7 \\
& Aluminium middle & 419 & 32 & 11.0 & 69 & 14.2 \\
& Aluminium back & 454 & 13 & 5.2 & 48 & 7.1 \\
\hline 9x19mm Para & Titanium front & 435 & 20 & 8.7 & 46 & NA \\
& Titanium middle & 417 & 26 & 9.9 & 58 & 4.2 \\
& Titanium back & 368 & 9.0 & 3.7 & 24 & 6.0 \\
.357" Magnum & Titanium front & 426 & 8.0 & 3.2 & 52 & 8.5 \\
& Titanium middle & 440 & 28 & 10.9 & 62 & 8.7 \\
& Titanium back & 458 & 5.0 & 2.0 & 19 & 2.9
\end{tabular}

Against the $9 \mathrm{~mm}$ bullet, the aluminium panel tended to petal with large cracks extending up to $25 \mathrm{~mm}$ away from the impact site. Compared with the results obtained without a metal plate, placing the plate in front of the aramid significantly increased the armours' ballistic resistance against $9 \mathrm{~mm}$ bullets (table 3). The metallic plate at the front was effective at deforming the $9 \mathrm{~mm}$ bullet and reducing the initial impact energy of the bullet before impact 
on the aramid pack. This resulted in a $92 \mathrm{~ms}^{-1}$ increase in ballistic performance $\left(339 \mathrm{~ms}^{-1}\right.$ to $431 \mathrm{~ms}^{-1}$ ) with a $10 \mathrm{~mm}$ reduction in backface deformation. The ballistic resistance against the .357" Magnum increased by only $23 \mathrm{~ms}^{-1}\left(445 \mathrm{~ms}^{-1}\right.$ to $\left.468 \mathrm{~ms}^{-1}\right)$ and very slight $(2 \mathrm{~mm})$ reduction in backface deformation. In both cases the change in backface deformation was not statistically significant.

Placing aluminium plates in the middle of the pack produced only slight changes in performance compared to the aramid alone and did not show the same increased performance of the front positioned plates. Also, the greatest backface deformations were measured when the plate was in the middle position.

The titanium results with the $9 \mathrm{~mm}$ ammunition follow the same trends as those of the aluminium, with the front position giving the best ballistic resistance and the rear position giving the lowest backface deformations. For the 0.357" Magnum, the effect of the titanium plate was negligible for all locations with ballistic resistance and backface deformation similar to the aramid by itself. The only exception being that the titanium plate at the back reduced the backface deformation by a factor of more than two.

\section{Discussion}

The energy delivered by the knife is absorbed by two mechanisms; direct resistance to penetration from the armour plate and backwards movement of the armour by dishing. Backwards movement of the armour also reduces the contact load allowing a given armour system to have an apparently better penetration resistance. The effect of introducing a relatively stiff metallic plate into an armour system is to restrict the backward movement of any elements placed in front of this layer. Therefore, it could be assumed that placing a metallic layer in front of an aramid pack would produce the best knife resistance, with middle or rear positioned metal layers being increasingly worse. The results for aluminium in Figure 5 showed that this was not the case, where aluminium plates in the middle gave the best performance and aluminium plates at the rear had the lowest performance.

The presence of even part of the aramid pack in front of the aluminium changes its failure mode from a brittle cutting failure to a ductile bursting failure. Although the cutting failure produces an initially higher resistive loads (fig. 6) the overall performance of the system is not as good as that achieved for the middle mounted plates (fig.5). Possibly the ability of the mid mounted plate to move backwards into the rear aramid layer reduces the contact load and allows more time and distance over which the perforation of the blade can be resisted.

Titanium panel armour had similar force profiles regardless of position with the only effect being a slight change in the initial force gradient. The titanium panel is relatively more flexible than the aluminium panel and stays in contact with the knife for longer during the event resulting in similar values for the peak loads for all three plate positions

This suggests that the dominant mechanism in the initial contact stage is the ability of the plate to move or deform rearwards. Whilst after perforation the dominant effect is frictional resistance between the knife and the metal plate. Previous work [7] has suggested that both these effects are present and provide the main components of knife resistance. 
Placing both types of metal plate in front of the aramid in the ballistic tests, allowed the plates to deform the bullet and absorb some energy before contact with the aramid pack. The bullet impact on the plate may also cause some acceleration of the aramid away from the bullet prior to direct contact reducing its relative velocity. These mechanisms improved the ballistic limit velocity but the backface deformations were unchanged compared to the aramid packs alone.

Placing the metal plates at the rear of the armour system restricted the movement of the aramid which reduced the ballistic limit. However, the packs deformed the projectile, absorbed energy and reduced the velocity before the projectile struck the metal layer. The plate then absorbed more energy from the projectile, which reduced the amount of backface deformation. Restricting movement reduces the distance and time the system has to stop the projectile and produce high contact stresses. These high contact stresses increased the deformation of both $9 \mathrm{~mm}$ and .357 " Magnum projectiles as the metal plates were moved from the front of the system, to the middle and the rear. The titanium plate was more ductile than the aluminium and had greater reductions in backface deformation. This was due to the titanium deforming in concert with the aramid and dissipating the impact loads over the surface of the witness block. Whereas the aluminium fractured and peeled back allowing the aramid to be pulled through the resulting hole. The most significant reduction in backface deformation was achieved by placing the titanium to the rear of the panel

Metal plates situated in the middle of the armour system resulted in relatively poor ballistic limit performance and greater backface deformation results. The ten layers of aramid in front of the metal were not sufficient to cushion the effects of the relatively stiff metal plate and prevented the aramid from moving and performing at its best. The remaining ten layers of aramid behind the plate is not enough to maintain the ballistic limit or stiff enough to control the backface deformation. For the 0.357" Magnum tests placing either plate in the middle position actually reduced ballistic limit velocity but the reduction was relatively small and was not statistically significant.

\section{Conclusions}

Placement of anti-stab systems within a dual purpose armour system is of importance, and can be used as a method of tuning the properties of that system to a particular requirement.

In complex stab resistant armour systems perforation resistance is a result of both the intrinsic resistance and mechanical interaction of the armour elements. In systems containing rigid and penetration resistant elements it is preferable to provide both forward and rearward cushioning so that stresses are transmitted ahead of the penetrating knife and rearwards movement is allowed in the direction of penetration. For a simple dual purpose armour system the optimum configuration is probably one in which the metallic knife resistant element is in the centre of the textile ballistic packs. This achieves good knife performance with only limited reduction in ballistic performance.

If a metal plate is placed on the front of a aramid armour pack to gain anti-stab performance, it is preferential for ballistic performance to make this layer as hard as possible. If however a metal plate is to be placed elsewhere in the armour system then a more ductile material is preferable. 
This work suggests that care should be taken if hard items or layers are positioned immediately behind a textile armour. Although no significant reduction in performance was observed in this work it should not be assumed that an extra layer will increase ballistic resistance.

\section{Acknowledgements}

The authors would like to acknowledge the efforts of A.M. Robertson in the completion of this research.

\section{References}

[1] Bazhenov, S., 1997, "Dissipation of Energy by Bulletproof Aramid Fabric" J. Material Science, 32(15), pp. 4167-4173.

[2] Montgomery. T. G., Grady. P. L., and Tomasino. C., 1982, "The Effects of Projectile Geometry on the Performance of Ballistic Fabrics", Textile Research Institute Journal, 52(7), pp. 442-450.

[3] Walker. J. D., 2001 , "Ballistic Limit of Fabrics with Resin”, TB46, Proc. 19th International Symposium on Ballistics, I. R. Crewther, ed., Interlaken, Switzerland, 3, pp. 1409-1429.

[4] Bhatnagar. A., 2004. "Bullet Deformation Characteristics in a Flexible Ballistic Vest", Proc. Personal Armour Systems Symposium 2004, J. L. M. J. van Bree, ed., The Hague, Netherlands, pp. 257-268.

[5] Tobin. L, Iremonger. M., 2006, Modern Body Armour and Helmets: An Introduction, Military Technology Series, Argos Press, Canberra, Australia, pp. 125, Chap. 9.

[6] Mamivand. M., Liaghat. G. H., 2010, "A Model for Ballistic Impact on Multilayer Fabric Targets” International J. Impact Engineering, 37(7), pp. 806-812.

[7] Horsfall. I., 2000, "Stab Resistant Body Armour", PhD Thesis, Cranfield University, UK. [8] Bottger. C., 2006, “Teijiin Twaron and Hybrids for Soft Body Armour" Proc. Personal Armour Systems Symposium 2006, P. Gotts, R. Horn, eds., Leeds, UK, pp.15-21.

[9] Schut. B. M., Tejani. N., "Tailored Offerings in Kevlar® and Nomex ${ }^{\circledR}$ for the Modern Soldier ", Proc. Personal Armour Systems Symposium 2004, J. L. M. J. van Bree, ed., The Hague, Netherlands, pp. 305-312.

[10] Jacobs. M. J. N., "New Performance Levels with Dyneema®UHMWPE Fibers and Dyneema ${ }^{\circledR}$ Uni-directional Ballistic Products”, Proc. Personal Armour Systems Symposium 2004, van Bree, J. L. M. J., ed., The Hague, Netherlands, pp. 279-283.

[11] Kevlar Aramid Fibre - Technical Guide, www2.DuPont.com [12] NATO STANAG 2920 (Ed 2), 2003, "Ballistic Test Method for Personal Armour Materials and Combat Clothing", North Atlantic Treaty Organization.

[13] Croft. J.,2007, "HOSDB Body Armour Standards for UK Police (2007)", Part 1-3, Home Office Publication No 39/07, UK.

[14] ISO/FDIS 14876-2, 2002 "Protective Clothing - Body Armour, Part 2 - Ballistic Resistance, Requirements and test methods", International Standards Organisation, Geneva, Switzerland.

[15] NIJ Standard-0101.06, 2008, "Ballistic Resistance of Body Armor”, National Institute of Justice, US Department of Justice, Washington, USA. 
[16] Money. M. W., and Sims. G. D., 1989, "Calibration of Quartz Load Cells; an in-situ Procedure for Instrumented Falling Weight Impact Machines”, Polymer Testing, 8(6), pp. 429-442.

[17] Parker. G., 1993, "Stab Resistant Body Armour Test Procedure”, Police Scientific Development Branch Publication No 10/93, UK.

[18] Watson. C.H., Horsfall. I., and Robertson. A. M., 1999, "Stacking Sequence Effects in Multi-Purpose Body Armour". Proc. Sharp Weapons Armour Technology Symposium, Cranfield University, UK.

[19] Robertson. A. M., 1998, “An Investigation into Multi-purpose Body Armour”, Mechanical Engineering Degree Project Report, Cranfield University, UK.

[20] Horsfall. I., Pollitt. S.M., Belk. J. A., and Angood. C., 1995, "Impact Perforation Testing of Stab Resistant Materials", Impact and Dynamic Fracture of Polymers and Composites, J. G. Williams, A. Pavan, eds., ESIS 19, Mechanical Engineering Publications, London, UK. 